\title{
Liquid Storage of Boar Semen Using Commercial Extenders
}

\author{
Liviu BOGDAN ${ }^{1}$, Mihai CENARIU ${ }^{1 *}$, Mihai BORZAN ${ }^{1}$, Simona CIUPE $^{1}$, Lehel SZABO ${ }^{1}$, Emoke PALL ${ }^{1}$ \\ ${ }^{1}$ University of Agricultural Sciences and Veterinary Medicine Cluj-Napoca, 3-5 Calea Manastur, 400372 \\ Romania. \\ *corresponding author: mihai.cenariu@usamvcluj.ro
}

Bulletin UASVM Veterinary Medicine 75(1)/2018

Print ISSN 1843-5270; Electronic ISSN 1843-5378

doi:10.15835/buasvmcn-vm:004617

\begin{abstract}
The research was focused on the modern evaluation of boar semen parameters, using computer assisted sperm analysis (CASA), before and after liquid storage at $15^{\circ} \mathrm{C}$. Semen was collected from 15 sexually mature boars by manual stimulation. Macroscopical and microscopical evaluation of semen was performed, followed by a detailed CASA analysis of all ejaculates. Subsequently, semen was diluted using 4 different extenders (Semtest, Androstar, MIII and Cronos) and stored at $15^{\circ} \mathrm{C}$ for 24 hours. Next, evaluation of progressive motility, total motility and viability was performed, using the same CASA system. All experiments were performed in triplicates and results were statistically analyzed. The average progressive motility after 24 hours was as follows: $69.56 \pm 6.38$ for MIII, $65.92 \% \pm 2.63$ for Semtest, $67.07 \% \pm 5.58$ for Androstar Plus and $68.93 \% \pm 3.40$ for Cronos. The viability results after 24 hours were: $86.34 \% \pm 1.38$ for Semtest extender, $93.55 \% \pm 3.38 \%$ for Androstrar Plus, $89.19 \% \pm$ 3.42 for MIII and $91.35 \% \pm 2.37$ for Cronos. The findings of this study suggest that the use of commercial extenders for short-term storage of swine semen is important in order to increase sperm longevity with minimal sperm function deterioration.
\end{abstract}

Keywords: boar semen, CASA, liquid storage

\section{Introduction}

Artificial insemination with freshly diluted or liquid stored boar semen led to the improvement of several important morphological features, but especially to increase in production. Several recent studies were made to show the influence of various extenders as well as bacterial contamination and supplementation with different antioxidants on the quality of liquid stored boar ejaculates at 15-17으 C (Fang et al., 2017; Schultze et al., 2017; Pinart et al., 2017).

Classical sperm analysis is based on the subjective evaluation of spermatic parameters, such as motility, viability and morphology. Currently, computerized semen analysis is used in many andrology laboratories and offers much more accurate data (Budworth et al., 1988; Cooper et al., 1999; Verstegen et al., 2002).
Compared to the established methods of analysis, the images obtained with these systems allow analysis of several spermatic parameters, such as: concentration, motility, morphology, degree of seminal DNA fragmentation, and especially seminal morphometry. Automatic image measurement systems in general and the Sperm Class Analyzer (SCA), in particular, are based on the sequential analysis of captured images coming from a microscope. These images are subsequently digitized, the sperm cells are identified and for each spermatozoon the trajectory is established. Eventually, results are generated in the form of reports. These results reflect a series of measurements derived from the two-plane analysis of the spermatozoa head over time (Foote, 2002; Cremades et al., 2005). 

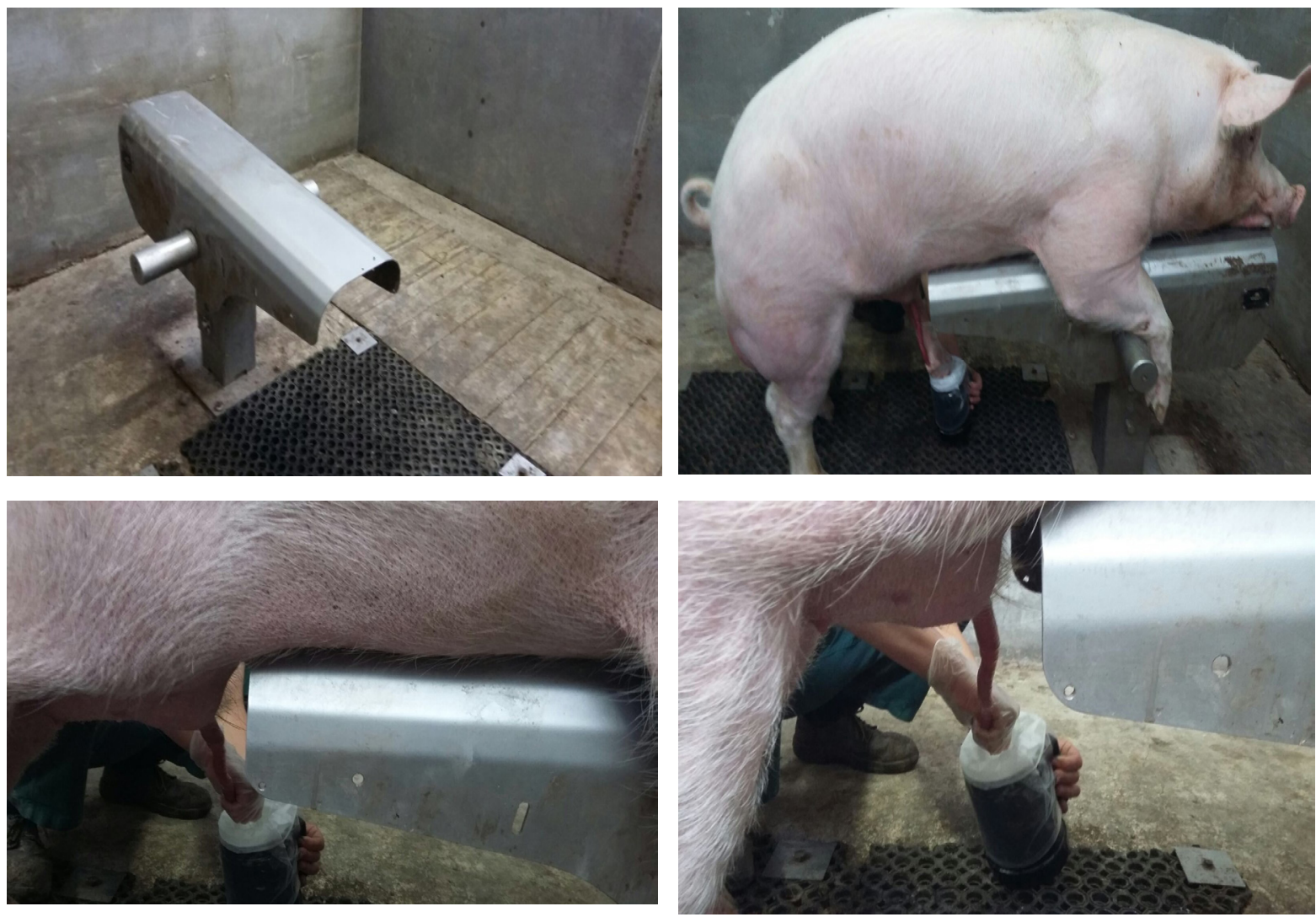

Figure 1. Semen collection in boars by manual stimulation

The result of the analysis depends on a number of factors such as the laboratory's climatic conditions, the semen volume, the storage conditions, the type of counting chamber, the status of the sperm population (fresh or frozen samples, concentration, extender used), as well as measurement systems (optics used, illumination type, instrument calibration) (Holt et al., 2007).

CASA systems are capable to objectively determine the morphological parameters and classification of spermatozoa in morphological categories, such as: normal and abnormal, spermatozoa with primary, secondary abnormalities, and also allow differentiation of different sperm subpopulations depending on motility or head shape (Mortimer, 2000).

Therefore, the current research was focused on the modern evaluation of boar semen parameters, using computer assisted sperm analysis (CASA), before and after liquid storage at $15^{\circ} \mathrm{C}$.

\section{Materials and methods}

Semen was collected from 15 sexually mature boars, belonging to four different breeds
(PIC337, Landrace, Pietrain and Great White) by manual stimulation (Figure 1). Macroscopical and microscopical evaluation of semen was performed followed by a detailed CASA (Sperm Class Analyzer ${ }^{\circledR}$ CASA System, Microoptic) analysis of all ejaculates.

Criteria for the inclusion of ejaculates in research were based on the following characteristics of the fresh material: white color, lactescent consistency, good sperm motility and viability.

Criteria for exclusion of ejaculates from the research referred to modified (abnormal) color, lack of motility and sperm viability.

Subsequently, each ejaculate was diluted using 4 different extenders (Semtest, Androstar, MIII and Cronos) and stored at $15^{\circ} \mathrm{C}$ for 24 hours. Dilution was carried out in two stages, namely, in the first instance, the initial dilution was carried out immediately after semen collection and sampling for the required examinations. Semen was introduced into double-walled graded flasks over which the same amount of diluent was added at $37^{\circ} \mathrm{C}(1: 1 \mathrm{v} / \mathrm{v})$. After $20-30$ minutes, which is required for equilibration at laboratory 
Table 1. Results of fresh semen analysis

\begin{tabular}{ccccc}
\hline Boar no. & Volume (ml) & Motility (\%) & Viability (\%) & Concentration \\
\hline B1 & 230 & $85 \%$ & $85 \%$ & $0.645 \times 10^{9}$ \\
\hline B2 & 219 & $95 \%$ & $95 \%$ & $0.578 \times 10^{9}$ \\
\hline B3 & 198 & $75 \%$ & $75 \%$ & $0.721 \times 10^{9}$ \\
\hline B4 & 267 & $75 \%$ & $75 \%$ & $0.429 \times 10^{9}$ \\
\hline B5 & 200 & $90 \%$ & $90 \%$ & $0.639 \times 10^{9}$ \\
\hline B6 & 365 & $85 \%$ & $85 \%$ & $0.768 \times 10^{9}$ \\
\hline B7 & 120 & $90 \%$ & $90 \%$ & $0.659 \times 10^{9}$ \\
\hline B8 & 416 & $75 \%$ & $75 \%$ & $0.468 \times 10^{9}$ \\
\hline B9 & 180 & $75 \%$ & $75 \%$ & $0.340 \times 10^{9}$ \\
\hline B10 & 182 & $75 \%$ & $75 \%$ & $0.623 \times 10^{9}$ \\
\hline B11 & 280 & $90 \%$ & $90 \%$ & $0.835 \times 10^{9}$ \\
\hline B12 & 250 & $85 \%$ & $85 \%$ & $0.779 \times 10^{9}$ \\
\hline B13 & 220 & $85 \%$ & $85 \%$ & $0.543 \times 10^{9}$ \\
\hline B14 & 340 & $90 \%$ & $90 \%$ & $0.876 \times 10^{9}$ \\
\hline B15 & 352 & $90 \%$ & $90 \%$ & $0.359 \times 10^{9}$ \\
\hline
\end{tabular}

temperature, final dilution was carried out with the extender at laboratory temperature.

The final dilution was made taking into account the following formula:

$G D=\frac{N \times a}{n}$

where: $\mathrm{GD}=$ dilution degree; $\mathrm{N}=$ total number of spermatozoa from the ejaculate; $a=$ motility; $\mathrm{n}=$ number of spermatozoa/insemination dose.

Each insemination dose was prepared at 90 $\mathrm{ml}$ with a concentration of $2 \times 10^{6}$ spermatozoa $/ \mathrm{ml}$.

Next, evaluation of progressive motility, total motility and viability was performed, using the same CASA system. For the motility analysis, the Leja $20 \mu \mathrm{l}$ chambers and the heating plate were used. An aliquot of $3 \mu \mathrm{l}$ was analyzed from each sample. The analysis was carried out by phase contrast, using the $10 \mathrm{x}$ lens and the green filter. Each captured field had a capacity of $512 \times 512 \times 8$, providing a digitized image of 264,144 pixels and 256 gray levels. The image resolution was 0.15 and $0.14 \mu \mathrm{m} /$ pixel on the horizontal and vertical axis, respectively. A total of 500 spermatozoa were analyzed from each sample. After completion of the analysis process, the system software automatically performs the detection of crosstrajectories, the calculations for the information obtained from each analyzed image, as well as all the fields, in order to calculate the average and the final result of the sample.
Viability assessment was performed using the FluoVit (Microoptic) kit. Thus, $10 \mu \mathrm{l}$ of Blue dye (FluoVit, Hoechst and Trihydrochloride trihydrate) solution, preheated to $37^{\circ} \mathrm{C}$, was added to $10 \mu \mathrm{l}$ of diluted sperm. The sample was incubated for 5 minutes at room temperature, after which $1 \mu$ of Red dye (FluoVit, propidium iodide) was added. The samples thus prepared were evaluated using the Nikon Eclipse C1 microscope, the Vitality module with the DAPI filter and the 20x lens. A total of 100 spermatozoa/sample were evaluated.

The entire experimental protocol was performed 3 times, at the second and third repeats using only diluents and concentrations with satisfactory results in the first experiment. The results were statistically analyzed using the GraphPad Prism program, and the results were expressed as averages \pm standard error (SE).

\section{Results and discussions}

The evaluation of fresh sperm was made in order to assess the quality of the ejaculates, which is essential for obtaining the best results after dilution and liquid storage. The evaluation of semen was focused on the determination of macro- and microscopic parameters specific to each individual boar, as follows (Table 1):

Based on these results, the ejaculates were diluted and transported to the Andrology Laboratory of the Faculty of Veterinary Medicine Cluj-Napoca. Samples were evaluated using the 
Table 2. Results obtained for fresh semen using the Sperm Class Analyzer CASA system

\begin{tabular}{cccccc}
\hline Boar no. & $\begin{array}{c}\text { Concentration } \\
\text { M/ml }\end{array}$ & $\begin{array}{c}\text { No. spermatozoa/ } \\
\text { sample }\end{array}$ & $\begin{array}{c}\text { Progressive motility } \\
\text { \% }\end{array}$ & $\begin{array}{c}\text { Total motility } \\
\text { \% }\end{array}$ & $\begin{array}{c}\text { Vitality } \\
\text { \% }\end{array}$ \\
\hline B1 & 19.73 & 1874.35 & 40.95 & 78.23 & 79.02 \\
\hline B2 & 16.44 & 1561.8 & 83.64 & 96.36 & 98.44 \\
\hline B3 & 25.25 & 2474.5 & 59.41 & 86.27 & 89.38 \\
\hline B4 & 27.12 & 2712 & 57.65 & 89.55 & 90.78 \\
\hline B5 & 37.3 & 3730 & 74.96 & 90.05 & 93.33 \\
\hline B6 & 30.68 & 3066 & 82.85 & 93.45 & 94.12 \\
\hline B7 & 24.13 & 2413 & 70.72 & 87.45 & 96.67 \\
\hline B8 & 27.33 & 2733 & 75.5 & 90.17 & 93.33 \\
\hline B9 & 27.78 & 2876 & 82.53 & 95.05 & 96.63 \\
\hline B10 & 30.75 & 3075 & 81.99 & 93.1 & 94.43 \\
\hline B11 & 17.4 & 1740 & 78.01 & 83.65 & 86.36 \\
\hline B12 & 18.19 & 1890 & 76.16 & 85.94 & 90.37 \\
\hline B13 & 20.29 & 2029 & 82.28 & 89.18 & 87.18 \\
\hline B14 & 16.76 & 1676 & 76.69 & 83.03 & 85.19 \\
\hline B15 & 23.45 & 2345 & 52.45 & 69.54 & 73.58 \\
\hline
\end{tabular}

Table 3. Overall analysis of average total motility after $24 \mathrm{~h}$ of storage

\begin{tabular}{ccccc}
\hline 24 h & \multicolumn{3}{c}{ Total motility } & \\
\hline & Semtest & Androstar Plus & MIII & Cronos \\
\hline PIC 337 & $85.86 \%$ & $90.77 \%$ & $83.2 \%$ & $91.7 \%$ \\
\hline Landrace & $87.89 \%$ & $91.34 \%$ & $89.21 \%$ & $89.34 \%$ \\
\hline Pietrain & $81.24 \%$ & $93.32 \%$ & $91.21 \%$ & $90.56 \%$ \\
\hline Great White & $81.32 \%$ & $89.32 \%$ & $87.45 \%$ & $87.32 \%$ \\
\hline Total & $84.07 \% \pm 1.65$ & $91.18 \% \pm 1.65$ & $87.76 \% \pm 3.41$ & $89.73 \% \pm 1.87$ \\
\hline
\end{tabular}

CASA system and the results were statistically evaluated. In order to perform the statistical analysis, the samples were evaluated in triplicate.

The average results are shown in Table 2 .

As shown above, total and progressive motility was superior for boars B2, B6, B9, B10, B13. Nevertheless, all of the ejaculates met the quality criteria for semen undergoing the storage process.

The most significant samples for each extender and breed were identified for re-evaluation after 24 hours. Total motility, progressive Type-A motility, progressive B-type motility, C-type nonprogresive motility, immotile D-type cells as well as viability were considered. The results obtained for every breed and extender are presented in the tables below:

The average total motility after 24 hours was $88.19 \% \pm 0.93$, while the best results were recorded for Androstar Plus where the average total motility was $91.18 \% \pm 1.65$, followed by the Cronos extender where average motility was $89.73 \% \pm 1.87$. Average motility for samples diluted with MIII was $87.76 \% \pm 3.41$, and for Semtest extender the average motility was $84.07 \% \pm 1.65$. Beside total motility, other sperm parameters were evaluated in each breed, as follows:

Overall analyzes of the results indicate that semen collected from the PIC 337 breed had the best qualities, where the average progressive motility after 24 hours of storage was $70.99 \% \pm$ 2.66 , compared to the rest of the breeds where progressive motility was $68.99 \% \pm 1.84$ for Landrace, $68.25 \% \pm 2.87$ for Pietrain and $63.24 \% \pm$ 2.35 for Great White. Nevertheless, the differences are not statistically significant.

Regarding the extenders used for semen dilution, the MIII extender showed best results in what progressive motility was concerned (the average progressive motility after 24 hours of liquid storage was $69.56 \pm 6.38$ ). The average 
Table 4. Sperm parameters in PIC337 after 24h of storage

\begin{tabular}{ccccc}
\hline PIC 337 & \multicolumn{3}{c}{} \\
\hline & Semtest & Androstar Plus & MIII & Cronos \\
\hline Progresive motility\% & 67.76 & 74.91 & 68.2 & 73.09 \\
\hline Non-progressive motility\% & 18.1 & 15.85 & 15 & 18.61 \\
\hline Non-motile\% & 14.14 & 9.23 & 16.8 & 8.3 \\
\hline Progresive motility type A\% & 18.97 & 20.03 & 19.6 & 11.8 \\
\hline Medium progresive type B\% & 48.79 & 54.88 & 48.6 & 61.21 \\
\hline Non progresive type C\% & 18.1 & 15.85 & 15 & 18.61 \\
\hline Non-motile type D\% & 14.14 & 9.23 & 16.8 & 8.3 \\
\hline Viability\% & 86.32 & 91.21 & 84.45 & 93.45 \\
\hline
\end{tabular}

Table 5. Sperm parameters in Landrace after $24 \mathrm{~h}$ of storage

\begin{tabular}{|c|c|c|c|c|}
\hline \multicolumn{5}{|l|}{ Landrace } \\
\hline & Semtest & Androstar Plus & MIII & Cronos \\
\hline Progresive motility\% & 65.21 & 63.7 & 78.43 & 68.65 \\
\hline Non-progressive motility\% & 12 & 14.43 & 4.32 & 12.65 \\
\hline Non-motile $\%$ & 10.6 & 12.64 & 6.46 & 8.04 \\
\hline Progresive motility type A\% & 20.21 & 24.16 & 23.21 & 25.3 \\
\hline Medium progresive type B\% & 45 & 39.54 & 55.22 & 43.35 \\
\hline Non progresive type C\% & 12 & 14.43 & 4.32 & 12.65 \\
\hline Non-motile type D\% & 10.6 & 12.64 & 6.46 & 8.04 \\
\hline Viability\% & 88.32 & 93.23 & 90.35 & 90.2 \\
\hline
\end{tabular}

Table 6. Sperm parameters in Pietrain after $24 \mathrm{~h}$ of storage

\begin{tabular}{|c|c|c|c|c|}
\hline \multicolumn{5}{|l|}{ Pietrain } \\
\hline & Semtest & Androstar Plus & MIII & Cronos \\
\hline Progresive motility\% & 68.21 & 67.2 & 68.4 & 69.21 \\
\hline Non-progressive motility\% & 8.3 & 13.5 & 12.6 & 12.8 \\
\hline Non-motile $\%$ & 4.73 & 12.62 & 10.21 & 8.55 \\
\hline Progresive motility type A\% & 24.3 & 21.09 & 25.21 & 21.3 \\
\hline Medium progresive type B\% & 43.91 & 46.11 & 43.19 & 47.91 \\
\hline Non progresive type C\% & 8.3 & 13.5 & 12.6 & 12.8 \\
\hline Non-motile type D\% & 4.73 & 12.62 & 10.21 & 8.55 \\
\hline Viability\% & 85.32 & 98.43 & 92.54 & 93.21 \\
\hline
\end{tabular}

progressive motility for Semtest was 65.92\% \pm 2.63, while the Androstar Plus and Cronos averages were $67.07 \% \pm 5.58$ and $68.93 \% \pm 3.40$, respectively.

The overall analysis of sperm cell viability results after 24 hours can be summarized as follows:

For the Semtest extender, the average viability was $86.34 \% \pm 1.38,93.55 \% \pm 3.38$ for the Androstrar Plus, 89.19\% \pm 3.42 for MIII and $91.35 \% \pm 2.37$ for Cronos. All four tested extenders have the ability to maintain the viability of sperm cells within normal limits, but satistically significant better results were obtained with Androstar Plus.

The overall better results obtained for Androstar Plus are probably due to the fact that this is a long-term extender for boar semen which also contains a CSP (cold shock protector).

The Computer Assisted Sperm Analysis (CASA) system provides information on the motility of each sperm cell in particular by processing sperm electronic images, reconstructing the trajectory of each sperm cell, simultaneously and objectively 
Table 7. Sperm parameters in Great White after 24h of storage

\begin{tabular}{ccccc}
\hline Great White & & & & \\
\hline & Semtest & Androstar Plus & MIII & Cronos \\
\hline Progresive motility\% & 62.5 & 62.5 & 63.21 & 64.78 \\
\hline Non-progressive motility\% & 8.9 & 13.6 & 12.3 & 11.2 \\
\hline Non-motile\% & 9.92 & 13.22 & 11.94 & 11.34 \\
\hline Progresive motility type A\% & 29.2 & 26.3 & 28.1 & 21.5 \\
\hline Medium progresive type B\% & 33.3 & 36.2 & 35.11 & 43.28 \\
\hline Non progresive type C\% & 8.9 & 13.6 & 12.3 & 11.2 \\
\hline Non-motile type D\% & 9.92 & 13.22 & 11.94 & 11.34 \\
\hline Viability\% & 85.43 & 91.34 & 89.43 & 88.56 \\
\hline
\end{tabular}

Table 8. Overall analysis of average progresive motility after $24 \mathrm{~h}$ of storage

\begin{tabular}{ccccc}
\hline & Semtest & Androstar Plus & MIII & Cronos \\
\hline PIC 337 & $67.76 \%$ & $74.91 \%$ & $68.2 \%$ & $73.09 \%$ \\
\hline Landrace & $65.21 \%$ & $63.7 \%$ & $78.43 \%$ & $68.65 \%$ \\
\hline Pietrain & $68.21 \%$ & $67.2 \%$ & $68.4 \%$ & $69.21 \%$ \\
\hline Great White & $62.5 \%$ & $62.5 \%$ & $63.21 \%$ & $64.78 \%$ \\
\hline
\end{tabular}

Table 9. Overall analysis of average viability after $24 \mathrm{~h}$ of storage

\begin{tabular}{ccccc}
\hline & Semtest & Androstar Plus & MIII & Cronos \\
\hline PIC 337 & $86.32 \%$ & $91.21 \%$ & $84.45 \%$ & $93.45 \%$ \\
\hline Landrace & $88.32 \%$ & $93.23 \%$ & $90.35 \%$ & $90.2 \%$ \\
\hline Pietrain & $85.32 \%$ & $98.43 \%$ & $92.54 \%$ & $93.21 \%$ \\
\hline Great White & $85.43 \%$ & $91.34 \%$ & $89.43 \%$ & $88.56 \%$ \\
\hline
\end{tabular}

evaluating each sperm component so that minor changes in sperm motility can be detected (Estienne et al., 2007, Gil et al., 2009).

Regarding the working methods, we consider that the computerized analysis of semen was an extremely useful method, being quick, easy to execute and very precise, removing the subjectivity in the evaluation of the parameters. The major disadvantage is the cost of purchasing the equippment, but also of the consumables, but in the case of a specialized laboratory processing a large amount of semen daily, it is a perfectly justified investment.

In order to produce pigs for fattening and to meet the needs of pork consumers, a large number of inseminations are carried out and management practices aim at maximizing success rates. This provides the opportunity to analyze large sets of data from optimized and standardized field conditions to determine whether the fertilization capacity of semen can be predicted by CASA parameters (Flowers, 2002).
Thus, the study confirmed that the method is very objective, demonstrating that the CASA system is very valuable for the selection of boar ejaculates, and implicitly for the selection of boars.

In the case of extenders, the findings of this study suggest that their use for short-term storage of swine semen is important to increase sperm longevity with minimal sperm function deterioration.

According to the storage conditions used in this study, all four types of diluents posses the necessary qualities to preserve the metabolic activity and integrity of the swine sperm membrane during short-term storage (up to 7 days) of liquid semen.

\section{Conclusion}

The findings of this study suggest that the use of commercial extenders for short-term storage of swine semen is important in order to increase sperm longevity with minimal sperm function deterioration. 
Acknowledgments. This research did not receive any specific grant from funding agencies in the public, commercial, or not-for-profit sectors.

\section{References}

1. Budworth PR,Amann RP, Chapman PL(1988). Relationships between computerized measurements of motion of motion of frozen-thawed spermatozoa and fertility. Journal of Andrology, 9: 41-54.

2. Cooper TG, Atkinson AD, Nieschlag E (1999). Experience with external quality control in spermatology. Human Reproduction, 14 : 765-769.

3. Cremades T, Roca J, Rodriguez-Martinez H, Abaigar T, Vazquez JM, Martinez EA (2005). Kinematic Changes During the Cryopreservation of Boar Spermatozoa. Journal of Andrology, 26: 610-618.

4. Estienne MJ, Harper AF, Day J (2007). Characteristics of sperm motility in boar semen diluted in different extenders and stored for seven days at $18^{\circ} \mathrm{C}$. Reproductive Biology, 7: 221-231.

5. Fang Q Wang J, Hao YY, Li H, Hu JX, Yang GS, Hu JH (2017). Effects of iodine methionine on boar sperm quality during liquid storage at $17^{\circ} \mathrm{C}$. Reprod Dom Anim, 52: 1061-1066.

6. Flowers WL (2002). Increasing fertilization rate of boars: Influence of number and quality of spermatozoa inseminated. J Anim Sci, 80: E47-E53.
7. Foote RH (2002). The history of artificial insemination:Selected notes and notables. J Anim Sci, 80: 1-10.

8. Gil MC, García-Herreros M, Barón FJ, Aparicio IM, Santos AJ, García-Marín LJ (2009). Morphometry of porcine spermatozoa and its functional significance in relation with the motility parameters in fresh semen. Theriogenology, 71: 254-263.

9. Holt WV, O’Brien J, Abaigar T (2007). Applications and interpretation of computer-assisted sperm analyses and sperm sorting methods in assisted breeding and comparative research. Reproduction, Fertility and Development, 19: 709-718.

10. Mortimer TS (2000). CASA - Practical Aspects. Andrology Lab Corner, 515-524.

11. Pinart E, Domènech E, Bussalleu E, Yeste $M$, Bonet $S$ (2017). A comparative study of the effects of Escherichia coli and Clostridium perfringens upon boar semen preserved in liquid storage. Animal Reproduction Science, 177: 65-78.

12. Schulze M, Ammon C, Schaefer J, Luther A-M, Jung M, Waberski D (2017). Impact of different dilution techniques on boar sperm quality and sperm distribution of the extended ejaculate. Animal Reproduction Science, 182: 138-145.

13. Verstegen J, Iguer-Ouada M, Onclin K (2002). Computer assisted semen analyzers in andrology research and veterinary practice. Theriogenology, 57: 149-179. 